\title{
REVIEW
}

\section{Unapproved Drugs in the United States and the Food and Drug Administration}

\author{
Alexander Nasr · Thomas J. Lauterio · Matthew W. Davis
}

Received: May 17, 2011 / Published online: September 1, 2011

(C) The Author(s) 2011. This article is published with open access at Springerlink.com

\section{ABSTRACT}

Despite more than a century of evolving federal legislation, there remain many unapproved drugs on the United States (US) market. This article reviews the history of drug approval in the US, beginning with the landmark Pure Food and Drug Act of 1906, through to the development of the US Food and Drug Administration (FDA). The Pure Food and Drug Act of 1906 was the first comprehensive federal legislation covering drug regulation. Intervening legislation, such as the Federal Food, Drug, and Cosmetic Act of 1938 and Kefauver-Harris Amendments in 1962, was later instituted. In June 2006, a century after the development of the FDA as an enforcement body, an initiative was undertaken to remove unapproved drugs from the marketplace. The Marketed Unapproved Drugs - Compliance Policy Guide outlines enforcement policies aimed at efficiently and rationally bringing all

Alexander Nasr · Thomas J. Lauterio ( $₫)$.

Matthew W. Davis

URL Pharma, Inc., Mutual Pharmaceutical Company,

Inc., 1100 Orthodox Street, Philadelphia, PA 19124.

Email: TLauterio@urlpharma.com unapproved and illegally marketed drugs into the approval process, or discontinuing their manufacture, distribution, and sale. The FDA has been actively pursuing control of unapproved drugs in recent years, with an approach concentrating on drug safety to ensure optimal public health and consumer protection.

Keywords: drug approval; FDA; unapproved drugs

\section{INTRODUCTION}

The United States (US) Food and Drug Administration (FDA) has grown over the past century, from a single, unidentified chemist in 1862 in the US Department of Agriculture to the present-day organization dedicated to promoting and protecting public health through the regulation of drugs and other products within its purview (Figure 1). The Pure Food and Drug Act of 1906 was the first comprehensive federal legislation covering drug regulation. This article reviews the history of drug approval in the US, from the landmark 1906 Act through significant intervening legislation and development of the FDA, culminating 
a century later when, in June 2006, the FDA announced an initiative to remove unapproved drugs from the marketplace, many of which remain illegally marketed. Final guidance for this initiative, the
Marketed Unapproved Drugs - Compliance Policy Guide, ${ }^{1}$ outlines enforcement policies designed to efficiently shepherd all such drugs through the approval process. In recent years, the FDA has stepped up its oversight

Figure 1. Timeline of the development of the FDA and subsequent regulatory actions. ${ }^{1}$ ANDA=Abreviated New Drug Application; CDER=Center for Drug Evaluation and Research; DESI=Drug Efficacy Study Implementation; FDA=Food and Drug Administration; GRAS/E=Generally Recognized as Safe and Effective; NDA=New Drug Application; OTC $=$ Over-the-counter.

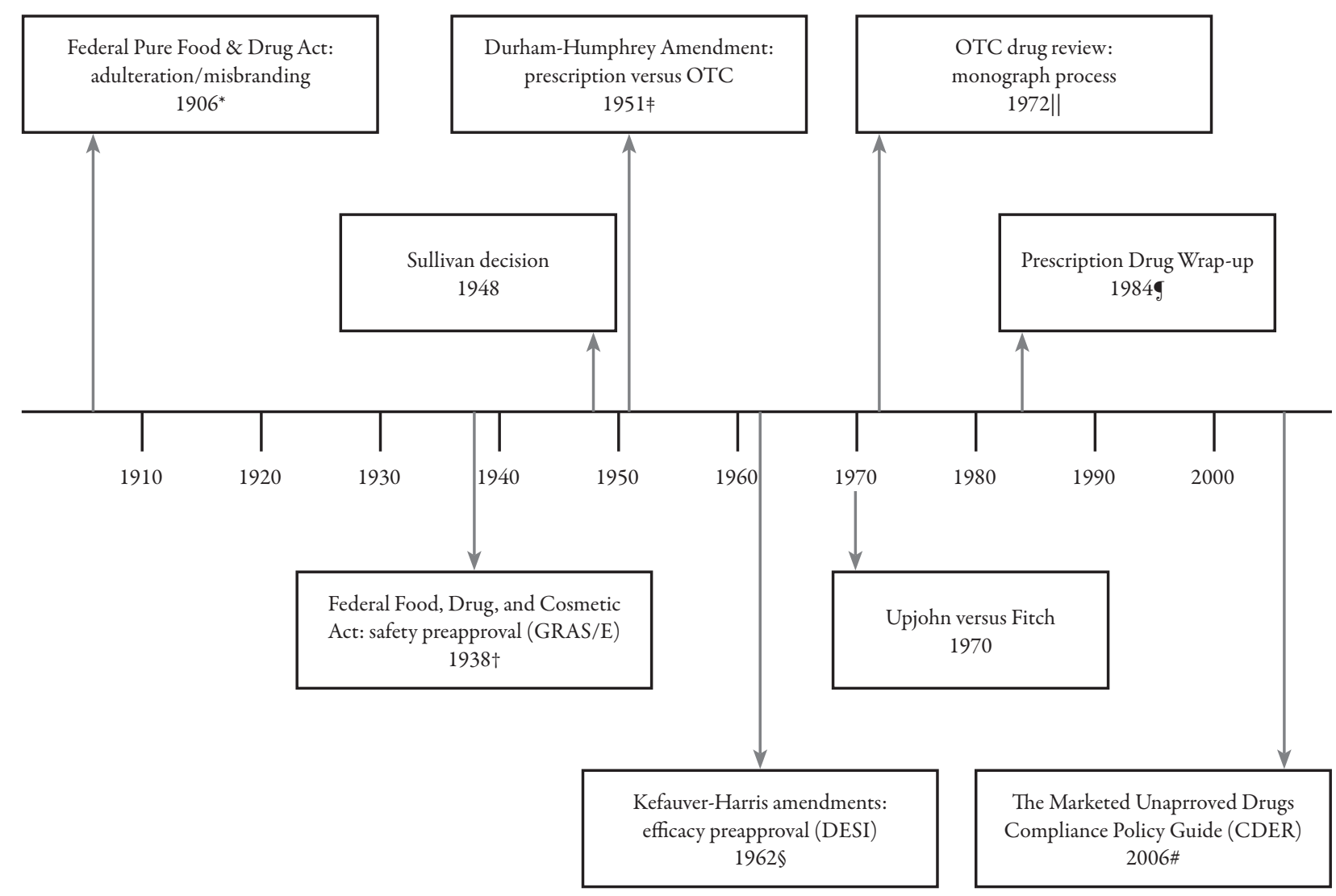

*Also known as the Wiley act; changed the government's handling of the adulteration and misbranding of food and drugs, and supported national food and drug regulation through public advocacy.

$\dagger$ Provisions included the ability of the FDA to require evidence of safety for new drugs, determine standards for food, and inspect factories.

¥Created the line between prescription and nonprescription drugs in that dangerous drugs could not be dispensed without a prescription and mandated that prescription drugs bear the following legend: "Caution: Federal law prohibits dispensing without prescription."

§Established the FDA's control over clinical drug trials and mandated "good manufacturing practices."

"OTC drugs marketed in accordance with a final monograph do not require approval of a marketing application by FDA.

SAlso known as DESI-2. Drugs are considered to be marketed illegally unless "grandfathered" or not otherwise a new drug. \#FDA's CDER; superseded previous policies of marketing new drugs without approved NDAs or ANDAs. 
and continues to actively pursue control of unapproved drugs, examples of which are also presented in this review.

\section{Methods}

A thorough search of the published literature, including that available on MEDLINE/PubMed, was used to identify the materials referenced in this manuscript. Specific search terms, including, but not limited to, FDA, history, development, compliance, nitroglycerin, thalidomide, colchicine, and DESI, were used to perform the comprehensive search. In addition, archived files from the FDA were also accessed.

\section{HISTORY OF DRUG APPROVAL IN THE US}

\section{The Pure Food and Drug Act of 1906}

Few federal laws to regulate the sale and contents of food and pharmaceuticals in the US existed prior to the creation of the Pure Food and Drug Act, which was signed into law in 1906 by President Theodore Roosevelt. This act is also known as the Wiley Act, in honor of its main advocate, Harvey Wiley, who is often referred to as the "Father of the FDA." Wiley was offered the position of Chief Chemist in the US Department of Agriculture in 1882. On assuming this role in 1883, he immediately changed the government's handling of the adulteration and misbranding of food and drugs, and supported national food and drug regulation by spurring public indignation over the issue. Motivated by his work with Alice Lakey, one million American women wrote to the White House in support of the Pure Food and Drug Act. ${ }^{2}$

Historically, under Wiley's guidance, the Bureau of Chemistry began analyzing the influence of preservatives on human nutrition in 1902, which extended to the analyses of proprietary medicines and plant drugs in the following year. ${ }^{3}$ These actions occurred at a time when the US marketplace was awash with adulterated food, drug, and biologic products. Drug makers were able to produce and sell products that, in today's marketplace, would be considered adulterated. For example, "Peter's Specific, The Great Blood Purifier System Regulator" was recommended as a treatment for dermatologic diseases and as an alternative tonic, invigorator, and blood purifier. ${ }^{3}$ The label stated little, if any, of the ingredients, yet it was available and sold legally in the US. Another example was morphine-laced "Mrs. Winslow's Soothing Syrup" used for teething and colicky babies. ${ }^{3}$

While Wiley realized the need for enforcement and change of this unregulated marketplace, it is widely believed that the 1906 "muckraking" novel The Jungle, by the Pulitzer Prize-winning American author Upton Sinclair, was the final driving force, resulting in a meat inspection law and a comprehensive food and drug law. ${ }^{4}$ Sinclair's novel exposed conditions in the US meat-packing industry and caused a public uproar, which contributed, in part, to the implementation of the Meat Inspection Act, as well as the Pure Food and Drug Act a few months after publication of the book. ${ }^{5}$

More than 200 laws would eventually follow the Pure Food and Drug Act of 1906, leading to one of the most comprehensive and effective public health and consumer protection networks in the world. The Bureau of Chemistry enforced the Act until 1927, when it was reorganized to establish the Food, Drug, and Insecticides Administration, which was renamed the FDA in 1931. ${ }^{5}$ The regulatory emphasis of the bureau during Wiley's tenure was foods, because he believed they presented more of a threat to 
public health than adulterated or misbranded drugs. After Wiley's resignation in 1912, more attention was focused on drug regulation, including the so-called "patent medicines."

\section{The Federal Food, Drug, and Cosmetic Act of 1938}

The next milestone in the evolution of the FDA was the Food, Drug, and Cosmetic (FD\&C) Act of 1938, which was passed after a series of disreputable incidents involving drug marketing claims which resulted in highly publicized deaths. One major incident involved the legally marketed Elixir Sulfanilamide, which killed at least 105 people, including many children, in the spring of $1937 .{ }^{6}$ Elixir Sulfanilamide, the first antimicrobial sulfa drug used to treat streptococcal throat and other infections, was available in liquid form through the dissolution of diethylene glycol, a known deadly poison normally used as an antifreeze. ${ }^{6}$ Under the thenexisting drug regulations, premarketing toxicity testing was not required. The resulting public outcry from this product not only propelled the bill through Congress, but also helped to reshape the drug provisions of the new law to prevent the reoccurrence of such an event. ${ }^{6}$

The FD\&C Act completely overhauled the drug regulatory system. Provisions included the ability of the FDA to require evidence of safety for new drugs, determine standards for food, and inspect factories. ${ }^{5}$ Previously, there had been no federal regulatory control ensuring the safety of new drugs. New drugs would require approval for safety through a New Drug Application (NDA). Those organizations that complete the process of submitting an NDA, and receive regulatory approval, obtain marketing exclusivity as a result, which may delay the entry of other approved competitor products into the market. ${ }^{5}$ However, holders of NDAs are not permitted to "manipulate statutory protections to inappropriately delay competition." Those who attempt to do so are then reported to the Federal Trade Commission (FTC). An NDA was not required under a "grandfather clause" for drugs marketed prior to 1938 that had been previously labeled as "Generally Recognized as Safe and Effective (GRAS/E)." They were required, however, to contain the same chemical composition, indications, and conditions for use as the "grandfathered drug." 5

The FD\&C Act of 1938 also mandated the listing of active ingredients on the drug label, and required labeling with adequate directions for use and warnings. By 1940, the FDA had developed more than two-dozen standardized warning statements for different drugs and determined that some drugs were too dangerous to be sold directly to consumers, even with labeled directions. In the 1948 US versus Sullivan case, the Supreme Court ruled that FDA jurisdiction extended to retail stores, thereby allowing the FDA to stop the illegal sales of drugs (eg, barbiturates and amphetamines) by pharmacies, defending the ability of the agency to define prescription-only drugs. ${ }^{1}$ The Durham-Humphrey Amendment of 1951 clarified the vague line between prescription and nonprescription drugs. Under the law, dangerous drugs, as defined by several parameters, could not be dispensed without a prescription. It also mandated that prescription drugs bear the following legend: "Caution: Federal law prohibits dispensing without prescription." 5

\section{Kefauver-Harris Amendments in 1962}

The Kefauver-Harris Amendments to the FD\&C Act (the 1962 Amendments) were considered the next major step, allowing the FDA stricter control over clinical drug trials. The Amendments also mandated "good manufacturing practices" for 
the drug industry, established a new level of responsibility for the FDA, and changed the way Americans viewed drug-product regulation and the FDA. For the first time, drug manufacturers were required to provide evidence of efficacy in addition to safety before marketing. In addition, the Amendments required disclosure of accurate side effect and efficacy information in advertising campaigns. As a result, previously marketed and inexpensive generic drugs could no longer be repurposed and marketed under more expensive, new trade names, labeled as new "breakthrough" medications. ${ }^{1}$ This major change in the regulatory powers of the FDA occurred in response to a series of incidents which made it clear that more public protection was needed, most notably of which were the well-publicized issues with thalidomide. ${ }^{7,8}$ Despite its approval, based on safety data, the safety review did not include the risk of teratogenicity. As a result, an estimated 10,000 victims were exposed to thalidomide globally and developed congenital abnormalities from this potent teratogen. ${ }^{7,8}$ The impact of thalidomide in the US was minimized when the NDA marketing application was denied by Dr Frances Kelsey and the FDA until further safety studies were conducted. ${ }^{9}$ Even though approval was never granted for marketing thalidomide in the US, more than two million tablets were distributed for investigational use as a result of a flaw in the law and regulations. The FDA moved quickly to recover this supply from physicians, pharmacists, and patients. ${ }^{5}$ However, a few cases of thalidomide-induced abnormalities nonetheless occurred in the US. ${ }^{10,11}$

As previously discussed, the Kefauver-Harris Amendments of 1962 required that all drugs introduced since the FD\&C Act of 1938 have demonstrated efficacy. ${ }^{1}$ However, a drug could be exempt from this requirement for several different reasons, including if there was no change in composition and labeling after 1962; it was used or sold on a commercial basis in the US before the 1962 Amendments became law; it was not a new drug as determined by the Act at that time; and it was not covered by an effective application. In other words, as long as a product was introduced to the market and contained the same representations regarding conditions of use as it did before the FD\&C Act of 1938, it was neither considered to be a new drug nor required to have an approved application. Again, drugs that were marketed before the passage of the 1938 Act were referred to as grandfathered drugs, that is, exempt as considered GRAS/E. A drug is not considered by the FDA to be grandfathered if, since 1938, there has been any change to formulation, dosage form, potency, route of administration, indication/labeling, or intended patient population. ${ }^{1}$

It is the responsibility of the manufacturer, or the distributor, of a grandfathered drug product to maintain files that contain the data and information necessary to fully document and support grandfathered status. The FDA believes that few, if any, genuinely grandfathered drugs remain on the market today. ${ }^{12}$ If a drug obtained approval between 1938 and 1962, the FDA generally permitted marketing of Identical, Related, or Similar (IRS) drugs to the approved drug without independent approval. A number of manufacturers introduced drugs to the marketplace between 1938 and 1962 on the basis of their own determination that the products were GRAS/E, and therefore exempt from the statutory new drug definition. ${ }^{12}$

In an effort to identify manufacturers who continued to market grandfathered drugs and bring them into compliance with federal regulations, the Kefauver-Harris Amendments mandated a retrospective efficacy evaluation of drugs approved between 1938 and 1962. ${ }^{1}$ In 1962, the FDA engaged the National Academy of Science/National Research Council 
(NAS/NRC) to review the efficacy of approximately 3,400 drugs that were previously approved, based on safety data. ${ }^{5}$ The review by the NAS/NRC was referred to as the Drug Efficacy Study (DES), with the results published in the Federal Register. From the findings, the FDA provided the Drug Efficacy Study Implementation (DESI) review. ${ }^{5}$ Therefore, drugs sold in the US between 1938 and 1962 that were approved for safety, but not efficacy, are now referred to as DESI drugs. Drugs that are IRS to DESI drugs are also called DESI drugs. ${ }^{1}$

The DESI program required approved NDAs for all marketed, unapproved prescription drugs, or Abbreviated New Drug Applications (ANDA) for IRS products. These drugs are deemed to be marketed illegally unless it can be proven by the manufacturer that the drug is truly not a new product requiring an approved application. ${ }^{5}$ These applications are termed "abbreviated" because they do not require preclinical and clinical trial data to establish safety and effectiveness, but must demonstrate bioequivalency to the branded product. ANDA are submitted to the FDA's Center for Drug Evaluation and Research, Office of Generic Drugs, for approval to manufacture and market these generic drugs as a safe, effective, lowcost alternative to branded products. These generic drugs, deemed to be comparable to branded products in dosage form, strength, route of administration, quality, performance characteristics, and intended use, are listed in the FDA's Approved Drug Products with Therapeutic Equivalence Evaluations (Orange Book). ${ }^{5}$

The efficacy review process was expedited in 1966 when the FDA contracted with the NAS/NRC to evaluate DESI drugs. ${ }^{1}$ By the end of 1981 , the agency had taken regulatory action on $90 \%$ of all DESI products, ${ }^{5}$ despite being challenged in 1970, whereby the Court of Appeals upheld enforcement of the 1962 drug effectiveness amendments in the Upjohn versus Fitch case by ruling that commercial success alone does not constitute substantial evidence of drug safety and efficacy. ${ }^{1}$

In 2007, there were fewer than 20 DESI proceedings pending review. ${ }^{12}$ In the event that the final DESI review determination classifies a drug as ineffective, the product and all its IRS products may not be marketed and are subject to enforcement action. Even if DESI and IRS products are found to be effective, the FDA still requires approval of applications as a condition of their continued marketing. Under these guidelines, DESI drugs still require an approved application; however, a drug with a DESIpending status does not require FDA approval and may be marketed until a final decision has been made and published in the Federal Register. ${ }^{12}$ Examples of outcomes for DESI drugs are shown in Table 1.

In summary, the 1962 Amendments eliminated drugs from the US market that were not proven to be effective, provided a means to require amendment of existing labeling to remain in compliance, gave new definition to the term "adequate and well-controlled studies," and provided an improved mechanism for the FDA to evaluate clinical trials. ${ }^{1}$

However, many drugs came onto the market before 1962 without approval from the FDA. Many of these products claimed to be marketed prior to the 1938 Act or to be IRS to such a drug, claiming grandfathered status. ${ }^{1}$ Drugs that did not have Amendments approvals before 1962 , or were not IRS to drugs with approvals before 1962, were not subject to DESI. The FDA allowed these drugs to stay on the market, in addition to allowing new, unapproved drugs that were IRS to these drugs from before 1962 to enter the market without approval for some time. There are an estimated five IRS products for every NDA product. ${ }^{1}$ 
In 1983, an unapproved, high-potency intravenous vitamin E (E-Ferol) caused adverse reactions in approximately 100 infants, 40 of whom died. ${ }^{13}$ This led to a 1984 Congressional Oversight Committee, which issued a report to the FDA expressing concern over the thousands of unapproved products on the market. This report led to an assessment of pre-1962 nonDESI marketed drug products by the FDA. The program for these marketed, unapproved drugs, instituted in 1984, became known as the Prescription Drug Wrap-up, often referred

Table 1. Drugs evaluated under Drug Efficacy Study Implementation (DESI).

\begin{tabular}{|c|c|c|}
\hline Products found ineffective under DESI & Manufacturer & Corporate headquarters \\
\hline Arlidin (nylidrin $\mathrm{HCl}$ ) & USV (Corvette) & Bombay, India \\
\hline $\begin{array}{l}\text { Combid (isopropamide iodide, prochloroperazine } \\
\text { maleate) }\end{array}$ & GlaxoSmithKline & $\begin{array}{l}\text { Raleigh-Durham, NC, } \\
\text { United States }\end{array}$ \\
\hline $\begin{array}{l}\text { Equagesic }^{\circ} \text { (meprobamate, ethoheprazine citrate, } \\
\text { acetylsalicate acid) }\end{array}$ & Wyeth Laboratories & Malvern, PA, United States \\
\hline $\begin{array}{l}\text { Marax (hydroxyzine } \mathrm{HCl} \text {, ephedrine sulfate, } \\
\text { theophylline) }\end{array}$ & Pfizer US Pharmaceuticals Group & New York, NY, United States \\
\hline $\begin{array}{l}\text { Neo-medrol }{ }^{\circ} \text { (methylprednisolone acetate, } \\
\text { neomycin sulfate) }\end{array}$ & Pharmacia and Upjohn Co. & Bridgewater, NJ, United States \\
\hline $\begin{array}{l}\text { Rautrax (raudixin, flumethiazide, potassium } \\
\text { chloride) }\end{array}$ & Bristol-Myers Squibb & Princeton, NJ, United States \\
\hline Tuss-Ornade (caramiphen, phenylpropanolamine) & GlaxoSmithKline & $\begin{array}{l}\text { Raleigh-Durham, NC, } \\
\text { United States }\end{array}$ \\
\hline Products found effective under DESI & Manufacturer & Corporate headquarters \\
\hline Thorazine ${ }^{\circ}$ (chlorpromazine) & GlaxoSmithKline & $\begin{array}{l}\text { Raleigh-Durham, NC, } \\
\text { United States }\end{array}$ \\
\hline Coumadin ${ }^{\circ}$ (warfarin) & Bristol-Myers Squibb & Princeton, NJ, United States \\
\hline Darvon $^{\circ}$ (propoxyphene) & Xanodyne Pharmaceuticals, Inc. & Newport, KY, United States \\
\hline Diuril $^{\bullet}$ (chlorothiazide) & Lundbeck Inc. & Deerfield, IL, United States \\
\hline Elavil $^{\circ}$ (amitriptyline) & Merck \& Co., Inc. & North Wales, PA, United States \\
\hline Librium (chlordiazepoxide) & $\begin{array}{l}\text { Valeant Pharmaceuticals } \\
\text { International }\end{array}$ & Ontario, Canada \\
\hline Nisentil ${ }^{\circ}$ (alphaprodine) & Hoffman-LaRoche, Inc. & Basal, Switzerland \\
\hline Methotrexate & Various & $\mathrm{N} / \mathrm{A}$ \\
\hline Heparin sodium & Various & $\mathrm{N} / \mathrm{A}$ \\
\hline Hydrocortisone acetate & Various & $\mathrm{N} / \mathrm{A}$ \\
\hline Isoniazid & Various & $\mathrm{N} / \mathrm{A}$ \\
\hline Isosorbide dinitrate & Various & N/A \\
\hline
\end{tabular}


to as DESI-2. ${ }^{13}$ The FDA claims that most of the approximately 5,000 unapproved, marketed drugs identified were pre-1938 and unapproved, pre-1962 drugs, or products that are IRS to such a drug. They also acknowledge that this list is incomplete and may include unapproved drugs from after $1962 .{ }^{13}$ The FDA believes that most Prescription Drug Wrap-up drugs first entered the market before 1938 in some form and had not been evaluated for safety or effectiveness. The FDA considers all drugs subject to the Prescription Drug Wrap-up to be marketed illegally, unless the manufacture of such a drug is grandfathered or not otherwise a new drug. ${ }^{13}$

Finally, some unapproved drugs were introduced to the market, or were changed, after enactment of the 1962 Amendments (ie, drugs not covered in the Prescription Drug Wrap-up). Other drugs were the subject of a formal new drug finding, defined as the introduction of a new delivery system of an approved drug. Examples include timed-release drugs and parenteral drugs in plastic containers. According to the FDA, drugs in this category are marketed illegally and are therefore subject to enforcement action unless covered by an NDA/ANDA. ${ }^{13}$

\section{CURRENT FDA POSITION ON MARKETED, UNAPPROVED DRUGS}

The FDA and the courts have interpreted the 1938 and 1962 grandfather clauses in the FD\&C Act in a limited fashion. The FDA contends that there are few, if any, drugs that are entitled to grandfathered status, because marketed drugs are likely to differ from the original versions in some respect (eg, formulation, dosage form, strength, manufacturing methods, route of administration, indications, and intended use in a specific patient population). Therefore, the FDA believes it is unlikely that any currently marketed drug is grandfathered or is otherwise not required to be FDA approved, but also recognizes that the existence of such drugs is theoretically possible. Over-the-counter (OTC) drugs were originally included in DESI, but the FDA eventually determined that it was not an effective use of resources to evaluate their status. As a result, the OTC Drug Review was instituted in 1972. ${ }^{13}$ The OTC Drug Review involved OTC rulemaking by therapeutic class (eg, antacids, cold remedies) using published monographs, setting forth permissible claims, labeling, and active ingredients for each therapeutic class. Monographs are defined as a statement that specifies the kinds and amounts of ingredients a drug, or class of drugs, may contain, the directions for use of the drug, the conditions in which it may be used, and the contraindications to its use. Drugs marketed in accordance with a final monograph are considered GRAS/E and do not require approval of a marketing application by the FDA. Unless the subject of an approved marketing application, OTC drugs are considered illegally marketed if approval is required because their ingredients or claims are not covered by the OTC Drug Review, or are not allowed as a result of a final monograph or another final rule. ${ }^{13}$ Figure 2 provides the FDA's decisionmaking tree for unapproved drugs. ${ }^{14}$

Because approximately 5,000 unapproved drug products continued to be marketed without required approval, the FDA implemented a risk-based enforcement program in June 2006 to focus its resources on products that pose the greatest threat to public health. ${ }^{1}$ The 2006 FDA initiative to remove unapproved drugs from the market included a final guidance entitled Marketed Unapproved Drugs - Compliance Policy Guide, ${ }^{1}$ which outlined enforcement policies designed to efficiently shepherd all such drugs through the approval process. This guidance was prepared by the FDA's Center for Drug Evaluation and 
Figure 2. Decision tree for unapproved drugs. ${ }^{14}$ Although this decision tree provides an overall approach to understanding how marketed unapproved drugs may comply with requirements under the FDA's current policies, as applied to any particular drug product, there may be variations and additional relevant factors. For instance, when a drug contains more than one active ingredient, each ingredient, as well as the combination as a whole, will need to be addressed. In addition, when an ingredient has been reviewed in more than one DESI proceeding, the agency will apply the regulation at 21 Code of Federal Regulation (CFR) 310.6 to determine which proceeding applies to a particular drug product. ANDA=Abbreviated New Drug Application; DESI=Drug Efficacy Study Implementation; NDA=New Drug Application; NOOH=Drug Efficacy Study Implementation Notice of Opportunity for Hearing; OTC=Over-the-Counter.

UNAPPROVED DRUG DECISION TREE

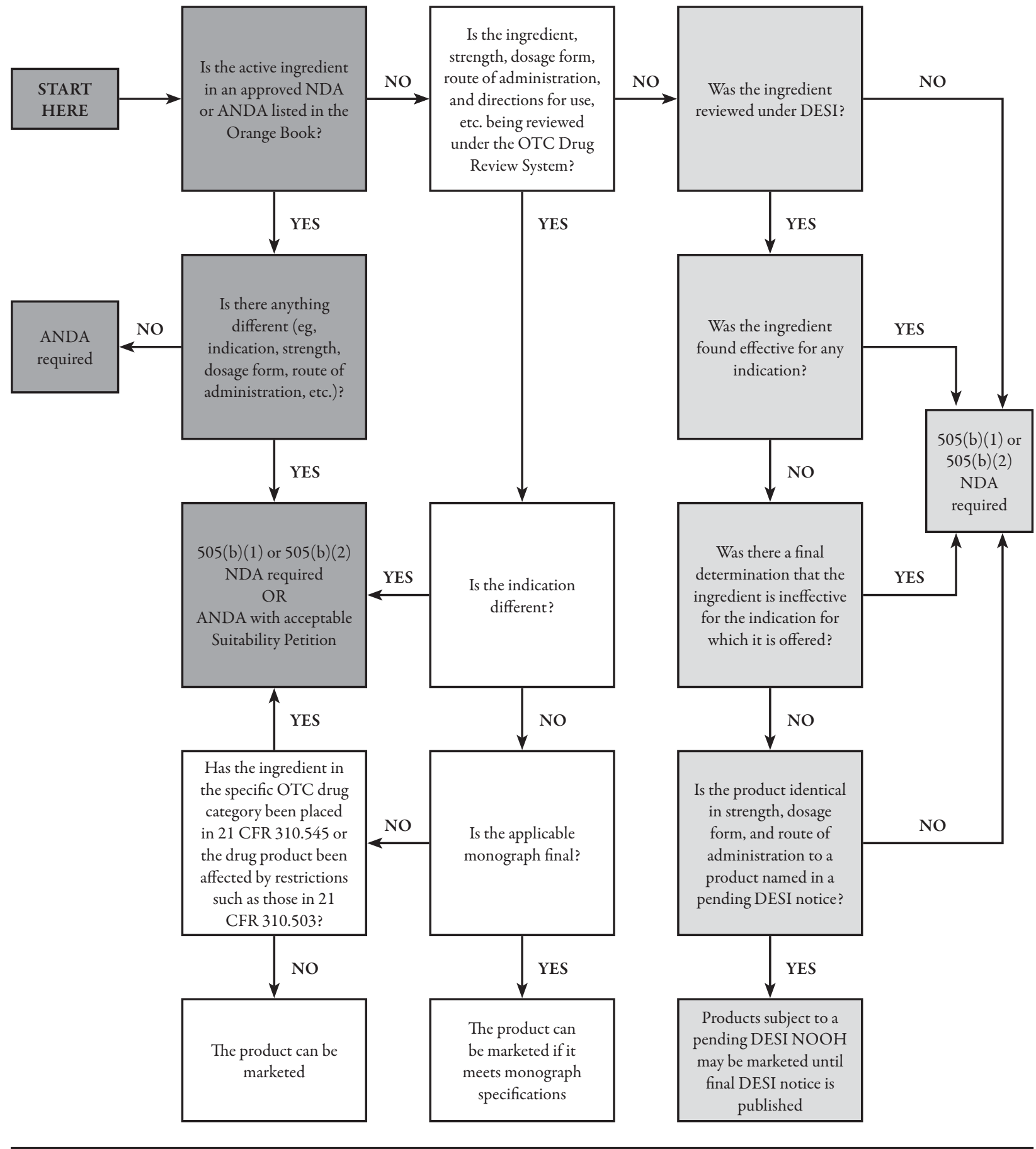


Research (CDER) and superseded previous policies on the marketing of new drugs without approved NDAs or ANDAs. ${ }^{1}$

The FDA can generally request voluntary compliance, post a notice of action in the Federal Register, present an untitled letter, issue a warning letter, and/or initiate a seizure, injunction, or proceeding to address the public health threat presented by an unapproved drug. However, these actions are time consuming and resource intensive. ${ }^{1}$ The intent of such guidance is to provide notice that an illegally marketed product is subject to FDA enforcement action at any time, which includes the provision of incentives for companies to obtain first-time approval for a previously unapproved drug, and allows for enforcement action against unapproved competitors of an approved product. ${ }^{1}$

The FDA advises that a warning letter may not be sent before enforcement action is initiated, and companies should not expect a grace period to protect them from leaving the market while obtaining approval. ${ }^{1}$ A grace period cannot be expected when public health requires a product to be immediately removed from the market or when specific prior notice has been given in the Federal Register, or otherwise, that a drug product requires approval from the FDA. ${ }^{1}$

\section{EXAMPLES OF FDA ENFORCEMENT AGAINST UNAPPROVED DRUGS}

To date, there are several notable and wellpublicized actions of FDA enforcement that have been taken against drugs with a previous unapproved status.

\section{Guaifenesin}

In 2002, warning letters were sent by the FDA to 66 pharmaceutical manufacturers that were marketing unapproved, single-ingredient, extended-release guaifenesin products, claiming that the products were illegally marketed new drugs. This action was initiated after one manufacturer filed an NDA for its single-ingredient, extended-release product (Mucinex ${ }^{\circledR}$; Reckitt Benckiser Inc, Berkshire, England), providing the FDA with the impetus for immediate enforcement. In 2007, the FDA required all competitors, after a grace period, to remove their products from the marketplace until an NDA was submitted. ${ }^{15}$ The FDA's enforcement action on unapproved competitors of an approved product, in this case, incentivized companies to obtain legal approval for a previously unapproved drug. ${ }^{15}$

\section{Carbinoxamine}

In June 2006, after having received 21 reports of deaths in children younger than 2 years of age, the FDA ordered all manufacturers of unapproved products containing the antihistamine carbinoxamine, including carbinoxamine maleate and carbinoxamine tannate, to discontinue production, despite the inability to establish a causal relationship. ${ }^{16}$ Some of these carbinoxaminecontaining products, used for the treatment of cough and cold symptoms, had been promoted for use in infants and children younger than 2 years and in those as young as 1 month of age. The FDA has since determined that this drug is neither safe nor effective for this indication in this patient population. This action did not affect tablets or oral solutions where carbinoxamine was the only active ingredient (tablet and oral solution, respectively). The manufacturer had received prior FDA approval to market these products for the treatment of allergic reactions or such symptoms in patients older than 2 years. ${ }^{16}$ 


\section{Levothyroxine}

Levothyroxine was being used as therapy by more than 15 million Americans when the FDA determined that it was necessary to bring formulations of this drug into compliance with current regulations. Although its safety and efficacy had been established in published medical literature, the FDA had concerns about the quality of the formulations in relation to their stability and potency in consideration of potential manufacturing issues. ${ }^{13}$

In 1997, the FDA issued a notice declaring that all orally administered levothyroxine products should be classified as new drugs, thereby requiring manufacturers to obtain NDAs. However, the manufacturers were given an initial 3-year grace period by the FDA, which was later extended to 4 years to allow continued marketing. Manufacturers had initially claimed that levothyroxine was exempt from FDA approval, claiming that it was in the same class as natural thyroid drugs and should therefore be grandfathered. On this basis, manufacturers attempted to obtain GRAS/E status from the FDA. This claim was subsequently rejected by the FDA, and all marketed levothyroxine products, following NDA submissions, are considered approved drugs by the FDA. ${ }^{13}$

\section{Nitroglycerin}

The recent action by the FDA on unapproved sublingual nitroglycerin tablets offers another example of enforcement in practice. Only one nitroglycerin product (Nitrostat ${ }^{\circledR}$; Pfizer Inc., New York, NY) has gained FDA approval, in 2000, following NDA submission. However, other sublingual, unapproved nitroglycerin tablets have been available for prescription from manufacturers claiming GRAS/E status. In March 2010, the FDA issued warning letters to the manufacturers of these unapproved nitroglycerin tablets to cease manufacture and shipment of existing products. ${ }^{17}$ The FDA did not accept the GRAS/E status of these formulations and had not reviewed the quality or labeling of these products, and it was noted that there had been significant problems related to quality and efficacy with some unapproved nitroglycerin products. ${ }^{18}$

\section{Colchicine}

Perhaps the greatest case for FDA action and oversight in this regard can be made for unapproved colchicine, the "poster child" for the need for FDA approval. Extracts of the alkaloid colchicine have been used since antiquity for the treatment of patients with gout. ${ }^{19}$ A relatively pure, oral formulation of colchicine was isolated and prescribed from the late 19 th century in the US and continued to be used, until recently, without having followed the formal FDA approval process for new drugs. Colchicine, therefore, escaped the obligatory, rigorous manufacturing standards and clinical studies to establish its efficacy and safety, as well as ancillary data for precise, reliable prescribing information, such as dosage recommendations, drug interactions, and use in special populations, that are required for new drugs by the FDA. ${ }^{19}$

Colchicine is metabolized to inactive metabolites by cytochrome P450 3A4 (CYP3A4)1 and is a substrate for P-glycoprotein (P-gp), ${ }^{20}$ a key protein in the multi-drug resistance (MDR)-1 transport system. It is excreted by both renal and hepatic mechanisms involving MDR-1-mediated efflux of colchicine. ${ }^{21,22}$ Plasma colchicine concentrations can therefore be significantly increased by renal or hepatic insufficiency ${ }^{23}$ and/or by concomitant administration of CYP3A4 or P-gp inhibitors, ${ }^{24}$ situations that are more frequent in the 
characteristically elderly population of patients with gout who are treated with colchicine. Furthermore, colchicine shows marked variability in disposition between individuals ${ }^{25}$ and its therapeutic index is narrow. ${ }^{25,26}$ High plasma colchicine concentrations cause characteristic diarrhea and, less frequently, serious and even fatal cases of myotoxicity and neurotoxicity. ${ }^{24-26}$

Colchicine is a prime example of an unapproved drug for which the FDA has enforced separate warnings for two different formulations. In February 2008, the FDA ordered all manufacturers of injectable colchicine, available since the 1950 s as an unapproved drug in the US, to cease manufacturing and shipment and submit NDAs for continued marketing. ${ }^{19}$ This action was initiated by the FDA due to significant safety concerns, including 167 deaths associated with the use of unapproved colchicine. The majority were at therapeutic doses, $<2$ g/day $(n=117)$, of which half $(n=60)$ were receiving clarithromycin concomitantly. ${ }^{27}$ There were 50 additional reports of serious adverse events (eg, neutropenia, acute renal failure, thrombocytopenia, congestive heart failure, and pancytopenia), 23 of which resulted in death. ${ }^{19}$ The FDA's action did not affect oral formulations, which continued to be marketed as unapproved drugs.

In 2009, the FDA approved three NDAs for single-agent, oral colchicine (Colcrys ${ }^{\circledR}$; Mutual Pharmaceutical Company, Inc., Philadelphia, PA), indicated for the treatment and prophylaxis of gout flares and familial Mediterranean fever. ${ }^{28}$ The FDA also took legal action against other companies that manufactured and/or distributed other, unapproved, oral formulations of colchicine based on false advertising and unfair competition theories. These unapproved oral formulations did not provide important safety data, instructions on drug interactions, or information on dosing that are provided in the prescribing information for the FDAapproved oral formulation, Colcrys. For example, the prescribing information for Colcrys provides important dosing information in relation to potentially fatal drug interactions. Additionally, the dose of Colcrys for acute gout flares, as defined in its prescribing information (determined from a phase 3 clinical trial and included in its NDA), is lower than previously prescribed for unapproved, oral colchicine formulations, thereby reducing the risk of toxicity while retaining efficacy. ${ }^{29}$ Finally, because FDA manufacturing standards were applied, new processes were developed to remove toxic derivatives of colchicine from purification that had previously been unregulated. This resulted in a much purer form of active ingredient while reducing toxic ingredients below the $0.06 \%$ level required by the FDA.

Despite the overwhelming safety concerns associated with the use of unapproved colchicine that occurred before the FDA's action to mandate the availability of single-source colchicine, controversy has been prominently raised. Primarily, this controversy arose in relation to increased acquisition costs for Colcrys without any proof of a meaningful improvement to public health. ${ }^{30}$ Yet, the true incidence of morbidity and mortality, and serious drug reactions associated with the use of unapproved colchicine, may be greatly underreported. From 2007 to 2008, the estimated prevalence of gout was 8.3 million adults, or $3.9 \%$ of the US population. ${ }^{31}$ A considerable proportion of these patients received unapproved colchicine, thus indicating a significant target population.

Given the lack of precise dosage recommendations, specific warnings for special populations (notably those with renal and/or hepatic insufficiency), and advice for dose adjustment during concomitant drug 
administration (notably CYP3A4 or P-gp inhibitors) as required for FDA-approved medications, it is probable that a considerable proportion of patients with gout were exposed to toxicity with unapproved colchicine. Indeed, gastrointestinal manifestations have been reported to develop frequently ( $91 \%$ of patients), ${ }^{26}$ which has limited the use of, and enthusiasm for, colchicine by patients. ${ }^{32}$ More overt and potentially fatal toxicity (myotoxicity and neurotoxicity, as well as bone marrow suppression) is associated with the higher colchicine exposure in patients receiving concomitant CYP3A4 or P-gp inhibitor administration, notably in those with intercurrent renal or hepatic insufficiency. ${ }^{26}$

Colcrys was approved for the treatment of acute gout attacks (as a single dose of $1.2 \mathrm{mg}$, followed by a dose of $0.6 \mathrm{mg} 1$ hour later) in adults. The registrational, randomized, doubleblind, parallel-group Acute Gout Flare Receiving Colchicine Evaluation (AGREE) trial compared the eventually approved, low-dose colchicine regimen of Colcrys (1.8 mg over 1 hour) with high-dose Colcrys (4.8 mg over 6 hours) and placebo in 184 patients with gout flare onset. ${ }^{31}$ Response rates ( $\geq 50 \%$ pain reduction at 24 hours without rescue medication) were $38 \%, 33 \%$, and $15 \%$ on low-dose Colcrys, high-dose Colcrys, and placebo, respectively. ${ }^{32}$ The incidence of adverse events was not significantly different between low-dose Colcrys and placebo (36\% vs. $27 \%$; odds ratio $=1.5$ [95\% CI, 0.7-3.2]), but was significantly higher $(77 \%)$ in the high-dose Colcrys group. Therefore, the approved low-dose regimen resulted in an efficacy profile comparable to that of the high-dose regimen, but with a safety profile indistinguishable from placebo. ${ }^{16}$

Currently, the prescribing pattern of practitioners' use of unapproved colchicine and Colcrys is not known, and it is also unknown whether or not the use of Colcrys has been definitively translated into improved patient safety. Investigations in this regard are ongoing.

\section{CONCLUSION}

The FDA defines legally marketed drugs as those that have an approved NDA (with generic versions of such drugs marketed under an approved ANDA) and those that are exempt from the FD\&C Act. The latter group includes pre-1938 and pre-1962 grandfathered drugs, products subject to ongoing DESI proceedings, GRAS/E prescription drugs, and drugs that are marketed in accordance with a final, or tentative, OTC monograph. Unapproved illegally marketed drugs include drugs marketed outside an OTC drug final, or tentative final, monograph, those found to be ineffective under DESI but for which an NDA/ANDA has not been submitted, drugs subject to the Prescription Drug Wrap-up Program, new unapproved drugs, and drugs not meeting GRAS/E requirements or that differ from pre-1938 or pre-1962 grandfathered drugs. The FDA has estimated that several thousand unapproved drugs exist within these categories.

The FDA currently gives priority status 'to enforcement action against unapproved drugs in the following categories: (1) drugs with potential safety risks; (2) drugs that lack evidence of effectiveness; (3) drugs that present a 'health fraud'; (4) drugs that present direct challenges to the 'new drug' approval and OTC drug monograph systems; (5) unapproved 'new drugs' that are also violative of the FDC Act in other ways (eg, Current Good Manufacturing Practice ['CGMP'] regulation violations); and (6) drugs that are reformulated to evade an FDA enforcement action (eg, when a firm, in anticipation of FDA enforcement action, changes its unapproved drug product by, for example, adding an active ingredient, in an attempt to evade such enforcement action). ${ }^{\prime 13}$ 
Finally, it is important to note that most of the unapproved drugs that have been targeted for enforcement by the FDA have lacked safety and/or efficacy data. A primary concern for the FDA remains the control of unapproved drugs in the market to ensure optimal public health and consumer protection.

\section{ACKNOWLEDGMENTS}

At the time of development of this manuscript, Dr Alex Nasr was employed by URL Pharma. Dr Thomas Lauterio and Dr Matthew Davis are currently employed by URL Pharma. The authors contributed significantly to the conceptualization, development, and review of this manuscript. Editorial assistance in the preparation of this manuscript was provided by Peter Todd, PhD, and James A. Shiffer, RPh, of Write On Time Medical Communications, LLC. Financial support for the development of this article was provided by URL Pharma, Inc. Dr Lauterio is the guarantor of this article, and takes responsibility for the integrity of the work as a whole.

Open Access. This article is distributed under the terms of the Creative Commons Attribution Noncommercial License which permits any noncommercial use, distribution, and reproduction in any medium, provided the original author(s) and source are credited.

\section{REFERENCES}

1. US Department of Health and Human Services. Food and Drug Administration Center for Drug Evaluation and Research (CDER). Marketed Unapproved Drugs - Compliance Policy Guide. June 2006. Available at: http://www.fda.gov/ICECI/ComplianceManuals/ CompliancePolicyGuidanceManual/UCM074382. Accessed March 26, 2011.

2. Fisher CD. Dr. Wiley and the Pure Food Laws. Progress. 1909;8:91-94.
3. Barkan ID. Industry invites regulation: the passage of the Pure Food and Drug Act of 1906. Am J Public Health. 1985;75:18-26.

4. Upton Sinclair. Encyclopædia Britannica. Encyclopedia Britannica Online. Encyclopedia Britannica, 2011. Available at: http://www. britannica.com/EBchecked/topic/545642/UptonSinclair. Accessed March 26, 2011.

5. Chhabrar R, Kremzner ME, Kiliany BJ. FDA policy on unapproved drug products: past, present, and future. Ann Pharmacother. 2005;39:1260-1264.

6. Ballentine C. Taste of raspberries, taste of death: the 1937 Elixir Sulfanilamide Incident. FDA Consumer Magazine, June 1981. Available at: http://www.fda.gov/AboutFDA/WhatWeDo/ History/ProductRegulation/SulfanilamideDisaster/ default.htm. Accessed March 26, 2011.

7. Moghe VV, Kulkarni U, Parmar UI. Thalidomide. Bombay Hosp J. 2008;50:472-476.

8. von Moos R, Stolz R, Cherny T, Gillessen K. Thalidomide: from tragedy to promise. Swiss Med Wkly. 2003;133:77-87.

9. Bren L. Frances Oldham Kelsey: FDA Medical Reviewer leaves her mark on history. FDA Consumer Magazine, Mar-Apr 2001. Available at: http://permanent.access.gpo.gov/lps1609/www. fda.gov/fdac/features/2001/201_kelsey.html. Accessed March 26, 2011.

10. Botting J. The history of thalidomide. Drug News Perspect. 2002;15:604-611.

11. Silverman WA. The schizophrenic career of a "monster drug". Pediatrics. 2002;110:404-406.

12. Autor DM. The Unapproved Universe. January 9, 2007. Available at: http://www.fda.gov/downloads/ AboutFDA/CentersOffices/CDER/ucm118338.pdf. Accessed March 26, 2011.

13. Karst KR. Marketed unapproved drugs: overview and FDA enforcement policies. August 10, 2006. Available at: http://www.hpm.com/pdf/ MARKETED\%20UNAPROVED\%20DRUGS-\%20 OVERVIEW.pdf. Accessed March 27, 2011.

14. Approved Drug Decision Tree. Available at: http://www.fda.gov/downloads/Drugs/Guidance ComplianceRegulatoryInformation/Enforcement ActivitiesbyFDA/SelectedEnforcementActions onUnapprovedDrugs/ucm 119916.pdf. Accessed March 27, 2011. 
15. US Department of Health and Human Services. Food and Drug Administration. Timed-release drug products containing guaifenesin; enforcement action. Federal Register. 2007;72:29517-29519.

16. US Department of Health and Human Services. Food and Drug Administration. Carbinoxamine products; enforcement action dates. Federal Register. 2006;71:33462-33462.

17. US Department of Health and Human Services Food and Drug Administration. Press release: FDA orders 2 companies to stop marketing unapproved nitroglycerin tablets. March 16, 2010. Available at: http://www.fda.gov/newsevents/ newsroom/pressannouncements/ucm204744.htm. Accessed March 27, 2011.

18. US Department of Health and Human Services. Food and Drug Administration. Questions and answers for consumers about FDA's action involving unapproved nitroglycerin sublingual tablets. March 16, 2010. Available at: http http:// www.fda.gov/Drugs/GuidanceComplianceRegulatory Information/EnforcementActivitiesbyFDA/Selected EnforcementActionsonUnapprovedDrugs/ucm204351. htm. Accessed March 27, 2011.

19. US Department of Health and Human Services. Food and Drug Administration. Drug products containing colchicine for injection; enforcement action. Federal Register. 2008;75:7565-7567.

20. Simkin PA, Gardner GC. Colchicine use in cyclosporine treated transplant recipients: how little is too much? J Rheumatol. 2000;27:1334-1337.

21. Speeg KV, Maldonado AL, Liaci J, Muirhead D. Effect of cyclosporine on colchicine secretion by a liver canalicular transporter studied in vivo. Hepatology. 1992;15:899-903.

22. Speeg KV, Maldonado AL, Liaci J, Muirhead D. Effect of cyclosporine on colchicine secretion by a kidney multidrug transporter studied in vivo. J Pharmacol Exp Ther. 1992;261:50-55.
23. Cocco G, Chu DCC, Pandolfi S. Colchicine in clinical medicine. A guide for internists. Eur J Intern Med. 2010;21:502-508.

24. Yang LPH. Oral colchicine (Colcrys) in the treatment and prophylaxis of gout. Drugs. 2010;70:1603-1613.

25. Niel E, Scherrmann JM. Colchicine today. Joint Bone Spine. 2006;73:672-678.

26. Finkelstein Y, Aks SE, Hutson JR, et al. Colchicine poisoning: the dark side of an ancient drug. Clin Toxicol (Phila). 2010;48:1422-1431.

27. Food and Drug Administration Information for Healthcare Professionals: New Safety Information for Colchicine. 2009. Available at: http://www.fda.gov/Drugs/DrugSafety/Postmarket DrugSafetyInformationforPatientsandProviders/ DrugSafetyInformationforHeathcareProfessionals/ ucm174315.htm. Accessed July 5, 2011.

28. US Department of Health and Human Services. Food and Drug Administration. Single-ingredient oral colchicine products; enforcement action dates. Federal Register. 2010;73:60768-60771.

29. Colcrys ${ }^{\circledR}$ Full Prescribing Information. September 6, 2010. Available at: http://www.colcrys.com/assets/ pdf/COLCRYS_Full_Prescribing_Information.pdf. Accessed March 28, 2011.

30. Kesselheim AD, Solomon DH. Incentives for drug development. The curious case of colchicine. N Engl J Med. 2010;362:2045-2047.

31. Terkeltaub RA, Furst DE, Bennett K, Kook KA, Crockett RS, Davis MW. High versus low dosing of oral colchicine for early acute gout flare: twenty-fourhour outcome of the first multicenter, randomized, double-blind, placebo-controlled, parallel-group, dose-comparison colchicine study. Arthritis Rheum. 2010;62:1060-1068.

32. Jayaprakash V, Ansell G, Galler D. Colchicine overdose: the devil in the detail. NZ Med J. 2007;120:U2402. 